\title{
Isometric exercise for acute pain relief: is it relevant in tendinopathy management?
}

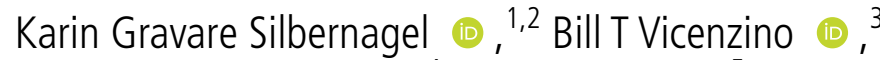 \\ Michael Skovdal Rathleff, ${ }^{4}$ Kristian Thorborg $^{5}$
}

Isometric exercise as an initial treatment and in-season pain management for tendinopathies has become the latest trend, yet clear evidence in support of this approach is lacking. This new approach is based on a small cross-over study $(n=6)^{1}$ and a small randomised control trial $(n=20)^{2} \quad$ comparing isometric and isotonic muscle contraction by Dr Ebonie Rio and colleagues. They reported substantial, acute effects of isometric exercise on pain in patients with patellar tendinopathy, which was greater than seen with isotonic exercise. While the pain relieving response of isometrics in the first trial $^{1}$ was dramatic and homogenic, the pain relief response of the second trial ${ }^{2}$ was much more heterogenic. Based on these results an isometric management approach was quickly extrapolated to other tendons, as evinced in a popular recently updated sports medicine textbook. ${ }^{3}$ We contend that three important questions need to be answered before isometric exercise is widely adopted as standard valid first step in tendinopathy management.

\section{QUESTION 1. WHAT IS THE STRENGTH OF THE EVIDENCE FOR ADOPTING} ISOMETRICS FOR TENDINOPATHY?

Does isometric contraction provide the strongest initial pain relief for tendinopathy? Four recent studies have addressed this question. ${ }^{4-7}$ UK's Dr Seth O'Neill et al tested the isometric protocol on 16 patients with Achilles tendinopathy and did not observe a meaningful positive group mean effect on pain or muscle

\footnotetext{
${ }^{1}$ Department of Physical Therapy, University of Delaware, Newark, Delaware, USA

2University of Delaware, Newark, Delaware, USA ${ }^{3}$ Physiotherapy, University of Queensland, Brisbane, Queensland, Australia

${ }^{4}$ Department of Clinical Medicine, Aalborg University, Research Unit for General Practice in Aalborg, Aalborg, Denmark

${ }^{5}$ Sports Orthopaedic Research Center-Copenhagen (SORC-C), Arthroscopic Center, Department of Orthopedic Surgery, Copenhagen University Hospital, Amager-Hvidovre, Denmark, Amager-Hvidovre Hospital, Hvidovre, Denmark
}

Correspondence to Dr Karin Gravare Silbernagel, Department of Physical Therapy, University of Delaware, Newark, DE 19716, USA; kgs@udel.edu recruitment. Some patients reported increased pain with the isometric contractions. ${ }^{4}$ Similarly, a randomised cross-over trial in 20 patients with plantar fasciopathy showed that isometric exercise was no better than isotonic exercise or walking in reducing pain. ${ }^{5}$ Comparable results were reported in a study of 24 patients with lateral elbow tendinopathy, with no change in pain free grip, and increased resting pain immediately following the intervention. ${ }^{6}$ But most importantly, the original study from Rio et al, could not be replicated in a pre-registered replication study using the same methods and outcomes in 20 individuals suffering from patellar tendinopathy.

\section{QUESTION 2: IS IT BENEFICIAL TO}

ACHIEVE ACUTE PAIN RELIEF IN INDIVIDUALS WITH LONGSTANDING TENDINOPATHY?

The argument for the benefit of isometric exercise is that it causes immediate pain relief and the recommendation is that progression to other exercise should not be pursued until pain has settled and the patient is proficient at isometrics. ${ }^{3}$ This ignores previous evidence in support of using isotonic exercise as the initial stage for tendinopathy treatment. Pain during exercise has not been found detrimental for recovery and to the contrary might even be beneficial. A change in focus from improving resilience to a focus on acute pain relief may likely misguide patients and clinicians into thinking there is a quick fix. Underscoring this premise is the evidence of continued functional deficits and altered muscle activation when pain free but without full tendon recovery. Promoting isometrics for immediate pain relief does not take the slow healing of the underlying pathology into account. We propose the focus on acute pain relief detracts from the important educational message that tendinopathy is a longstanding condition that takes many months to resolve and warrants ongoing monitoring and management. Recovery from tendinopathy is not best measured by reduction in pain immediately, and $45 \mathrm{~min}$ post-treatment. In addition, the potential adverse effect of acutely loading a painful tendon in sporting activities after a substantial and sudden symptom reduction is still unclear.

\section{QUESTION 3: HAS ISOMETRICS PROVEN SUPERIOR IN TENDINOPATHY MANAGEMENT?}

As in-season management, there have been suggestions of immediate pain relief following both isometrics and isotonics in athletes with patellar tendinopathy $(n=20-29)$, without any between-group difference. ${ }^{8}$ This is consistent with finding of no superiority of isometrics over isotonics for acute patellar tendon pain relief. Recent large scale studies with sample sizes in excess of 600 suggest that maintained pre- and in-season strengthening and conditioning without any specific bias towards concentric, isometric or eccentric modes reduce the in-season prevalence of shoulder and groin problems (approx. 30\%-40\%). Furthermore, there is evidence that using a pain-monitoring model and adequate adaptation periods during rehabilitation will enable continued sporting without adverse effect on recovery.

\section{TENDINOPATHY MANAGEMENT TAKE- HOME}

The main message is that adopting new management approaches without adequate evidence is problematic, especially when this is inconsistent with prevailing evidence that tendons require time to adapt to adequate and appropriate loading. The hasty implementation of new trends without solid evidence potentially results in extended time and effort to de-implement ineffective management approaches. We should not ignore isometric exercise, but thoroughly investigate if and how it aids the management of patient with tendinopathies. Until further evidence arises, clinicians should feel comfortable and confident to prescribe progressive strengthening that fits the individual athlete and progress following current evidence-based principles of load and exercise progression.

Contributors All the authors have contributed equally to the conception, writing and revising of the manuscript and have approved the final manuscript.

Funding The authors have not declared a specific grant for this research from any funding agency in the public, commercial or not-for-profit sectors.

Competing interests None declared.

Patient consent for publication Not required.

Provenance and peer review Not commissioned; externally peer reviewed. 
(C) Author(s) (or their employer(s)) 2019. No commercia re-use. See rights and permissions. Published by BMJ.

\section{D) Check for updates}

To cite Gravare Silbernagel K, Vicenzino BT, Rathleff MS, et al. Br J Sports Med 2019;53:1330-1331.

Accepted 30 April 2019

Published Online First 10 May 2019

Br J Sports Med 2019:53:1330-1331. doi:10.1136/bjsports-2019-100591

\section{ORCID iDs}

Karin Gravare Silbernagel http://orcid.org/0000-00017566-407X

Bill T Vicenzino http://orcid.org/0000-0003-0253-5933

\section{REFERENCES}

1 Rio E, Kidgell D, Purdam C, et al. Isometric exercise induces analgesia and reduces inhibition in patellar tendinopathy. Br J Sports Med 2015;49:1277-83.

2 Rio E, van Ark M, Docking $S$, et al. Isometric contractions are more analgesic than isotonic contractions for patellar tendon pain: an In-Season randomized clinical trial. Clin J Sport Med 2017;27:253-9.

3 Brukner P, Clarsen B, Cook J, et al. Brukner \& Khan's clinical sports medicine. 5 ed. New South Wales: McGraw-Hill Education Australia, 2017.

4 O'Neill S, Radia J, Bird K, et al. Acute sensory and motor response to $45-\mathrm{S}$ heavy isometric holds for the plantar flexors in patients with Achilles tendinopathy. Knee Surg Sports Traumatol Arthrosc 2018. doi:10.1007/s00167-018-5050-z. [Epub ahead of print: 04 Jul 2018].

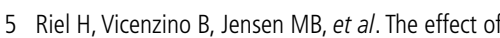
isometric exercise on pain in individuals with plantar fasciopathy: a randomized crossover trial. Scand I Med Sci Sports 2018:28:2643-50.

6 Coombes BK, Wiebusch M, Heales L, et al. Isometric exercise above but not below an individual's pain threshold influences pain perception in people with lateral Epicondylalgia. Clin J Pain 2016:32:1069-75.

7 Holden S, Lyng K, Graven-Nielsen T, et al. Isometric versus isotonic exercise for acute analgesia in patellar tendinopathy- does contraction type matter? A randomised crossover trial. Presented at the Scandinavian Sports Medicine Conference, Copenhagen, Denmark, 2019

8 van Ark M, Cook JL, Docking SI, et al. Do isometric and isotonic exercise programs reduce pain in athletes with patellar tendinopathy in-season? A randomised clinical trial. J Sci Med Sport 2016;19:702-6. 